\title{
Playwork: a profession challenging societal factors devaluing children's play
}

\author{
Michael Matthew Patte \\ Distinguished Fulbright Scholar of Playwork and \\ Associate Professor of Education \\ Bloomsburg University \\ Bloomsburg, Pennsylvania, USA \\ Fraser Brown \\ Reader in Playwork \\ Leeds Metropolitan University \\ Leeds, UK
}

\begin{abstract}
In this paper we examine the intensification of attitudes devaluing play in modern society and current research across multiple disciplines linking the absence of play to negative effects for children. We argue that the field of playwork, popular in Scandinavian countries and elsewhere in Europe, endorses a core set of principles that address many societal factors devaluing play in the lives of children.
\end{abstract}

\section{Introduction}

Play has been a constant in the lives of American children for generations. Engaging in outdoor play provides hours of unstructured fun to experience various colours, sights and sounds that etch vivid memories and impressions. Such experiences stimulate the senses, invigorate the spirit and enliven the soul. But are opportunities for play available for children today, or are they a fading memory from the nostalgic past?

While fond memories of play abound for grown-ups, they are lacking for many children. Attitudes towards play as being frivolous, impractical and unproductive are pervasive in our postmodern world (Patte 2009). Both in the classroom and in the 
living room, play has changed from being an unstructured, child-initiated endeavour to an adult-directed activity stressing early academic preparation. What has caused the change? Marano (2008) and Sigel (1987) blamed invasive parenting and hothousing techniques that attempt to control the conditions in which children develop. These authors suggested that such approaches are ruled by fear and tend to remove opportunities for children to solve problems, thus creating a fragile and easily discouraged generation.

Further, Elkind (2007) characterised the individualistic and competitive nature of our society as a breeding ground for anxious adults concerned about their child's place atop the global economy. In such an environment, play is viewed as a luxury the contemporary child can ill afford. The dwindling amount of time devoted to selfdirected play over the past twenty years is stark. During this period, children have lost 12 hours of free time a week, including eight hours of unstructured play and outdoor activities (Elkind 2007). In contrast, the amount of time children spend in organised sports has increased by 50 per cent from 1981 to 1998 (Hofferth 1999). Even in preschool, play has taken a back seat to more structured learning activities. Just 30 years ago, 40 per cent of a typical preschool day was devoted to childinitiated play, compared with 25 per cent today (Miller and Almon 2009).

\section{Societal factors devaluing children's play in America}

The sights and sounds of children playing outdoors are a hallmark of any thriving, robust community. However, due to a variety of societal factors devaluing play, many opportunities for children's play in America have been lost. These societal factors that serve as barriers to play include fear, access to quality play spaces, increased amounts of screen time, and a reduction in school-based playtime.

Fear in its many forms serves as a major societal barrier impeding play opportunities for American children. According to both Elkind (2007) and Gill (2007), parental fear causes parents to overinvest, overprotect and overprogram the lives of their children. One factor associated with parental overinvestment is the shrinking size of the American family. For a variety of reasons, families in America are smaller today than in the past, making it easy for parents with fewer children to be highly invested in their child's education, social group and extracurricular activities. Such an investment can cause parents to feel responsible for each success and failure in their child's life. Further, role strain is an additional factor related to parental overinvestment. According to Parsons (1968) as society becomes more sophisticated so do the social roles of its participants. Therefore it follows that, as many of the child-rearing functions once performed by parents are now shared with others, parents tend to overinvest in the functions still under their control.

Overprotection is a second way parental fear is actualised around children's play in America. In general terms, parents in the 1930s and 1940s were more concerned with protecting children's innocence and less concerned about risks to children's physical wellbeing. During this era families were bigger, homes were smaller, and children had greater access to outdoor spaces. Children were often encouraged to play outside and spend vast amounts of time without adult supervision. Taking and managing risks was a natural and accepted aspect of living in the real world and a 
vital component in the development of independence. Today, however, parents' concern for their child's physical wellbeing is more prominent than their concern to protect childhood innocence, despite the fact that there is no statistical evidence to suggest that children are in more physical danger today than in the past. Examples of this shift can be seen in the sheer number of parents who use cell phones to keep track of their children at all hours of the day and in the increased number of children now participating in organised sports under the watchful eyes of adult coaches (Elkind 2007). These contemporary fears about children's physical wellbeing do have an impact on play opportunities. For instance, when children are kept from playing on their own they are deprived of opportunities to be innovative and to manage risk, both skills necessary for success in the twenty-first century (Marano 2008).

Finally, overprogramming the lives of children constitutes a third way parental fear concerning play is actualised in America. This fear is often associated with parents feeling they are not doing enough to help their children develop at an accelerated pace. Further, the fear is enhanced through sophisticated marketing of educational toys and learning materials targeted to young children. With so much to choose from, parents are often left asking themselves how much is too much. Elkind (2007) recommended resisting the temptation to enrol children in organised sports prior to the age of five or six, as doing so makes participation an obligation and not truly play. He suggests that children will obtain appropriate amounts of exercise and preparation for participation in future sports through natural everyday play opportunities. Such opportunities allow children to choose and move between their favorite play activities, to manage risk, and to develop social relationships with a variety of children.

Gaining access to quality play spaces is a second barrier affecting opportunities for play in America (Colabianchi et al. 2009). In a recent poll, 59 per cent of parents reported that there was no outdoor play space within walking distance from their home; in lower socioeconomic neighbourhoods the number jumped to 69 per cent (KaBoom 2009). Yet eight in ten parents believe it is important for such facilities to be within walking distance from their homes (Floriani and Kennedy 2008). Even in communities where play spaces do exist, accessing them is proving difficult due to the recent trend towards limiting their availability. For example, school playgrounds and other community gathering places that were once accessible to the public are now off limits due to liability concerns. Professional organisations with a vested interested in the wellbeing of children like the American Academy of Pediatrics advocate opening school playgrounds and community gathering places to promote opportunities for physical activity (Ginsberg 2007). In addition to these public spaces being accessible to children and families, they must also be safe. According to Sallis and Glanz (2006) safety and the perception of safety are the most important factors for parents when selecting play spaces for their children.

The prevalence of technology in the lives of children makes screen time an additional barrier affecting time for their play. The amount of time children spend engaged in screen time has worried parents, teachers and researchers for years (Luke 1990). During the past two decades, American children were active participants in 
an explosion of mass media. Screen time in a variety of forms (watching television and videos and playing video and computer games) has all but replaced more active and creative play opportunities for American children. For example, in 2000, 97 per cent of American homes with children owned a television, 97 per cent owned a videocassette recorder, while 89 per cent owned a personal computer or other video game equipment (Federal Trade Commission 2000). Over 70 per cent of American homes owned at least one television, 69 per cent owned cable television, and 15 per cent purchased a satellite television service (Comstock and Sharrer 1999). Presently, children under the age of six spend roughly two hours each day interacting with screen media (Rideout, Vandewater and Wartella 2003), while children between the ages of 8 and 18 average 6.5 hours of screen time each day totalling more than 45 hours each week (Stanford University 2007). Recommendations for the healthy development of children advocate active lifestyles and avoiding sedentary pursuits.

The elimination and reduction of recess and play in school demonstrates the diminished value placed on play throughout American society. Our schools are now contributing to the suppression of curiosity, imagination and fantasy through the elimination of recess in favor of more time for academics (Elkind 2007). For example, since 1990, 40 per cent of the nation's 16,000 school districts have either modified, deleted or are considering deleting recess from the daily elementary school schedule due to increased pressure to improve achievement (American Association for the Child's Right to Play 2004). Further, over 40,000 schools throughout the country no longer have recess and those that do average between 15 and 20 minutes per day (Marano 2008; Patte 2009). Even in preschool, play has taken a back seat to more structured learning activities as time devoted to play has decreased from 40 per cent in 1981 to 25 per cent in 1998 (Miller and Almon 2009). Further, the use of prescriptive curricula has all but eliminated creative and playful teaching practices.

\section{Consequences of devaluing children's play in America}

Consider the following research across multiple disciplines that links the absence of play to negative effects for children:

- Underdeveloped social skills. School violence, emotional outbursts and underdeveloped social skills for engaging with peers and authority figures are all growing issues for schools today. Presently teachers spend increasing amounts of time on classroom management and less time actually teaching (KaBoom 2009, p. 6). The KaBoom report suggests the absence of play is a major contributing factor.

- Increasing diagnoses of attention deficit hyperactivity disorder (ADHD). Four and a half million children between 3 and 17 years of age $(7 \%)$ are diagnosed with ADHD (CDCP 2007, p. 5). Further, more than twenty-one million prescriptions are written each year for stimulant drugs to enhance attention, mostly in children aged 6-14, a 400 per cent increase over a decade (Marano 2008). Both Marano (2008) and Else and Sturrock (1998) suggested the absence of play is a major contributing factor. 
- Lack of resilience. According to Marano (2008) lacking exposure to the sort of challenges experienced during play impairs the ability to develop coping skills and the inner resources necessary to adapt to a fluid world.

- $\quad$ Poor health. Due to a lack of physical activity childhood obesity rates have almost tripled since 1980 , increasing from 6.5 per cent to 16.3 per cent (Robert Wood Johnson Foundation 2009).

- Heightened levels of anxiety and depression. Diagnoses of anxiety disorders and depression in children are on the rise, with a corresponding increase in the use of psychoactive drugs to treat them. For example, antidepressant use in children has risen 333 per cent over the past decade (Marano 2008). Marano suggested that the absence of play is a contributing factor.

- $\quad$ Decrease in creativity and imagination. According to Pink (2005) students of the twenty-first century need to be able to thrive in an imagination economy where people produce things that cannot be outsourced, things typically associated with artistic, empathetic and playful abilities.

- $\quad$ Lack of flexibility. Animal researchers argue that play serves as training for the unexpected. Bekoff and Pierce (2009) posited a 'flexibility hypothesis', namely that play helps animals learn to switch and improvise all behaviours more effectively. Further, they suggested that play is of vital importance in the development of creativity and flexibility so that children are able to cope when they encounter unexpected situations and new environments.

- Inability to assess and manage risk. Marano (2008) aptly described America's risk adverse epidemic, and it is mirrored in the United Kingdom (Gill 2007).

These trends, which we have also observed through our personal experiences as an elementary school teacher and academic spanning twenty years, motivated us to explore possible solutions to societal factors devaluing children's play in America. The field of playwork, popular in Scandinavian countries and the United Kingdom, endorses a variety of principles that seem well suited to accomplish this daunting task.

\section{The role of playwork in addressing societal factors devaluing children's play}

In the book Playwork: theory and practice playwork was described as 'a mechanism for redressing aspects of developmental imbalance caused by a deficit of play opportunities' (Brown 2003, p. 52). It follows, therefore, that the playwork approach is well suited to address the societal factors devaluing children's play in America. Nevertheless, there is a need for caution in the practical application of that approach. It would be wrong to infer from this definition that playworkers see play solely as part of the child's preparation for adulthood, or that their role is something Sturrock called 'adult-generated corrective adjustment' (2007, p. iii). Playwork is not about 
adults taking control of children's lives; quite the opposite. Playworkers see children as 'the subjects of their own development', and play as a process of both 'being and becoming' (ibid). It is only during play that children are likely to experience being in control of their own destiny. In practice, playwork is substantially about creating environments that enable children to play freely. The most effective playwork environment, therefore, has little intervention from the playworker once the basic parameters have been set. Put simply, the role of the playworker is to provide the setting, the tools and the materials, and leave the rest to the children, albeit having regard for their safety and security. In the words of John Portchmouth, 'It helps if someone no matter how lightly puts in our way the means of making use of what we find' (1969, p. 7).

However, as we have already discussed, many modern environments contain elements that act against the play process. Therefore, the initial task of the playworker is usually to analyse the environment in order to identify and remove any barriers to the children's play. This could mean something complex like negotiating the closure of a busy street to remove a traffic danger; or something simple like picking up broken bottles that have somehow found their way onto the outdoor space of an after-school club. Sometimes the playworker will be acting as an advocate for children whose voice is not being heard. In some cases the barriers are not obvious, and the playworker will need to get to know the local culture before being able to judge what the real obstacles are. In many modern communities one of the biggest obstacles to free play is the priority accorded to adult rights over children's rights, and in particular Article 31 of the UN Convention on the Rights of the Child, which recognises the child's right to play (UNICEF 1991).

Having identified, and hopefully removed, the barriers to play, the playworker's next task is to enrich the child's play environment in order to stimulate the play process. This has sometimes been interpreted as a form of 'scaffolding', a concept developed by Bruner et al. (2010) to describe the way in which an adult might provide a carefully designed structure to enable children to learn. That level of adultled intervention would not be accepted in the playwork approach. Although intervention is sometimes necessary, in all cases the child's agenda has to be taken as the starting point for playwork interventions. Enriching the play environment is not about promoting an adult agenda of specific learning outcomes, but rather adopting an holistic approach to development, and accepting that children are 'competent to meet their play needs' so long as they are given appropriate opportunities (Melville 1999, p. 71). A number of factors have to be taken into account when considering how best to create a play-friendly environment. These have been summarised as: freedom; flexibility; socialisation and social interaction; physical activity; intellectual stimulation; creativity and problem solving; emotional equilibrium; self-discovery; ethical stance; adult-child relationships; and the general appeal of elements such as humour, colour, and so on (Brown 2003, p. 64). There is a striking synergy between these elements and the detrimental factors that emerge through the loss of play, summarised previously in this article.

For many playworkers the most significant theory underpinning their work is compound flexibility, that is, 'the interrelationship between a flexible/adaptable 
environment and the gradual development of flexibility/adaptability in the child' (Brown 2003, p. 53). According to Sutton-Smith the function of play is 'adaptive variability' (1997, p. 231). Taking these two concepts together we can infer that the role of the playworker is to create flexible environments that are substantially adaptable or controllable by the children. One way of doing this is to ensure there are lots of 'loose parts' in the play environment. When explaining his 'theory of loose parts', Nicholson suggested that 'in any environment both the degree of inventiveness and creativity, and the possibility of discovery, are directly proportional to the number and kind of variables in it' (1971, p. 30). Thus, a room full of cardboard boxes, packing crates, old clothes and so on is more likely to stimulate creative play than a fixed climbing frame.

Playwork also seeks to encourage the growth of confidence and self-esteem. This is achieved in part by providing an environment that is both physically safe and personally secure, but nevertheless offers children the opportunity to take risks and experience challenges. In that regard we are not speaking only of physical experiences, but also social and emotional ones. For example, every time a child jumps out from behind a tree and shouts 'boo' at another child, s/he is taking a risk. At best the result may be an extension of friendly play. At worst the action may result in rejection or even violence. A good quality playwork experience will offer children the opportunity to initiate risky behaviour, sometimes within a secure context, but not always. Indeed the respected playwork writer Bob Hughes says 'because of its powerful role in the development of survival skills, a comprehensive play experience must contain a measure of actual risk taking behaviour, i.e. behaviour where at least the possibility of pain and/or injury is real' (1996, p. 19).

In contrast to this very open-handed approach, the safety lobby has had a powerful influence in recent years, with the result that children's playgrounds tend to be less adventurous today. However, this overprotective lobby may well have had its day in the UK. In its recent position statement the UK Play Safety Forum said: 'Risk-taking is an essential feature of play provision, and of all environments in which children legitimately spend time at play’ (Play Safety Forum 2008, p. 2).

One of the most significant elements of the playwork approach is the way in which relationships are made with the children. If the child-adult relationship is effective, there is a good chance of not only helping children with their problems, but also raising their self-esteem generally. Most adults who come into contact with children bring their own agenda to that relationship. For example, teachers have an obligation to teach an agreed curriculum (a set of adult priorities). Doctors, social workers, even parents, invariably have their own adult priorities. The playworker is unusual in as much as s/he attempts to suspend personal prejudice, and go along with the flow of the children's needs and tastes.

This brings us to the concept of 'negative capability'. The poet John Keats (1817) suggested this was a characteristic of all creative minds. He recommended the complete suspension of all prejudices and preconceptions as a prelude to opening up the creative flow of the mind. In the modern era this is reflected in the words of the jazz musician Miles Davis who, when asked to reflect on his unique ability, 
explained it thus: 'You need to know your horn, know the chords, know all the tunes - then forget about all that, and just play' (Sanjek 1990, p. 411). Fisher (2009) explored the similarity between this approach to creativity and one of the most fundamental aspects of the child-adult relationship in playwork. He suggested that playworkers have to guard against entering the play environment with their own preconceptions and prejudices. Only then will they truly be there for the child. This approach requires a great sensitivity to the learning potential of the playwork setting, and means the playworker has to be prepared to stand back when others might be inclined to rush in.

Thus, the decrease in our children's imagination and creativity highlighted in the earlier paragraphs of this article is addressed in the playwork approach both by the demeanour of 'negative capability' adopted by the playworker, and also by the access to a 'loose parts' environment offered within the playwork setting.

Else and Sturrock (1998) suggested that the relentless reduction of children's opportunities to play in modern society has led to heightened levels of anxiety and depression, and possibly to the rise in the incidence of ADHD. Sutton-Smith touched on this issue in his classic comment: "the opposite of play is not work, it is depression' (1999, p. 254). It is certain that the recent reduction in physical activity, and specifically informal play, has led to an increase in obesity and poor health. Indeed Mackett et al. (2009) have shown that children are more active, and use more calories, when engaging in free play than in equivalent organised activities, to say nothing of the largely passive time spent in front of a screen. Clearly the playwork approach, which makes a virtue of freedom of access and freedom of choice, and so provides opportunities for informal play, is ideally suited to addressing the obesity issue.

A further concern expressed at the beginning of this article was children's poorly developed social skills and general lack of resilience. In an ideal world children learn and develop both while they are playing and through their play - the child's interactions with his/her environment and with other children are a fundamental part of development. Our personal experience of play enables us to develop a range of human attributes that enable us to cope easily with the complexity of human relationships. We are born with the potential to develop the attributes of sympathy, empathy, affective attunement and mimesis, but without social play that potential will remain untapped. This is dangerous because it is likely to leave children struggling to understand the behaviour patterns of those around them, and unable to offer appropriate signals to initiate effective social interaction. By replacing the play opportunities that have gone missing from children's lives in recent years, playworkers are contributing to the development of some very fundamental psychosocial skills.

Else and Sturrock (1998) highlighted the importance of playworkers being able to interpret children's play cues. They suggest that a failure to do so accurately, and to offer appropriate responses, may actually exacerbate the development of childhood psychoses. Children's cueing behaviour may range from something as simple as an invitation to play, all the way through to more complex and possibly ambiguous 
mimetic behaviour. However, this should not be regarded as any sort of obstacle to an adult's ability to work effectively with children. Sutton-Smith (1997) spoke of the role of play in actualising the brain's potential. One example of this would be the way in which play enables us to develop the above-mentioned human attributes of sympathy, empathy, affective attunement and mimesis, and so make appropriate responses to children's play cues.

Adam Smith (1976) suggested that human beings are innately sympathetic to each other, and that it is the human capacity for mimesis that makes this interpretation possible. Through fantasy, invention and symbolic play, humans are able to use parts of the body to describe almost anything, and we do not find it hard to interpret another person's representations. For example no-one needs to train us to understand the subtle nuances of a child pretending to be a horse. We may think the only clue we need is the fact that the child is sitting astride a broom handle, but that on its own would not be enough. The child will actually be exhibiting a range of very complex behavioural clues, including the way the broom handle is being held, the fact that the child is trotting, rather than running, and so on. Although these signs are many and varied, we nevertheless have no difficulty in putting them together and interpreting them accurately. To quote Donald:

Mimesis rests on the ability to produce conscious, self-initiated, representational acts ... Thus, mimesis is fundamentally different from imitation and mimicry in that it involves the invention of intentional representations. When there is an audience to interpret the action, mimesis also serves the purpose of social communication. (1991, pp. 168-169)

Human beings are probably the only animals able to symbolise meaning in their actions in this way. For Trevarthen (1996), mimesis is a talent that gradually develops, and play is the catalyst. In other words, we learn how to interpret other people's play cues while we are playing. Although, as we have seen, this is not a difficult skill to develop, the uniqueness of the playwork approach lies in the playworkers' steady attunement of their awareness to the children's behaviour patterns. Put simply, playworkers, unlike any other adults who work with children, are 'on the lookout' for play cues, and will respond accordingly.

Daniel Stern's concept of 'affective attunement' (1985) is also something we may learn while we are playing. Stern did not suggest that. He focused instead on the mother-baby relationship, and was interested in the way mothers become attuned to their baby's rhythms. That makes it possible to demonstrate to the baby ways in which its actions might be further developed. For example, if an object is just out of reach, a baby may have to make a double movement in order to grasp it. The mother is likely to clap her hands twice, or make a sound 'ah-ah', in exactly the same rhythm as the baby's grasping action. This apparently simple interaction contains some very complex subtexts. The obvious message is 'I am in tune with you', but there is a more subtle and far more powerful message: 'I can help you translate your actions into a different form.' Stern linked most of his ideas to the mother-baby interaction. However, we now have evidence from work in Romania that affective attunement can easily be achieved by an empathetic adult working with a severely disturbed child (Brown and Webb 2005). 
To summarise, sympathy, empathy, mimesis, affective attunement and the sensitive interpretation of play cues are essential skills for the playworker. They are skills that are easily absorbed and developed during our own play during childhood; however, it is doubtful whether they could be learnt within the confines and structures of today's classroom.

\section{Conclusion}

In an earlier text Brown (2008) suggested that in playwork settings children's learning and development derive substantially from the playworkers' ability to create an enriched play environment that is supportive of the play process. The playworkers' use of negative capability, their suspension of judgement and prejudice, coupled with a determination to take each child's agenda as his/her own starting point, helps to create a good quality playwork environment - in other words, an environment that offers adaptability to the children, and so encourages the compound flexibility process. Through their empathy, and their ability to interpret the children's play cues effectively, playworkers are able to create strong trusting relationships, which in turn help to enhance the children's self-esteem. If such approaches were applied in informal settings in America, children might be expected to cope well with their immediate world, and also to develop naturally. This straightforward playwork approach works very effectively in the UK in settings as diverse as adventure playgrounds, after-school clubs, hospitals and prisons. It is an approach that has even worked in Romania with some of the most play-deprived children in the world. Consequently, within the play-deprived context of contemporary America, incorporating a playwork approach into childhood settings seems essential.

\section{References}

American Association for the Child's Right to Play 2004, Recess news, www.ipausa.org/recess.htm.

Bekoff, M and Pierce, J 2009, Wild justice: the moral lives of animals, University of Chicago Press, Chicago, IL.

Brown, F 2003, Playwork: theory and practice, Open University Press, Philadelphia, PA.

Brown, F 2008, 'The fundamentals of playwork' in Foundations of Playwork, ed. F Brown and C Taylor, Open University Press, Maidenhead, pp. 7-13.

Brown, F and Webb, S 2005, 'Children without play', Journal of Education, vol. 35, pp. 139-158.

Bruner, JS, Caudhill, E and Ninio, A 2010, 'Language and experience' in John Dewey reconsidered, ed. R Peters, Routledge, Abington, pp. 18-34. 
Centers for Disease Control and Prevention 2007, Summary health statistics for US children: national health interview survey, US Government Printing Office, Washington, DC.

Colabianchi, N, Kinsella, AE, Coulton, CJ and Moore, SM 2009, 'Utilization and physical activity levels at renovated and unrenovated school playgrounds', Preventive Medicine, vol. 48, no. 2, pp. 140-143.

Comstock, GA and Sharrer, E 1999, Television: what's on, who's watchin', and what it means, Academic Press, San Diego, CA.

Donald, M 1991, Origins of the modern mind, Harvard University Press, Cambridge, MA.

Elkind, D 2007 The power of play: how spontaneous, imaginative activities lead to happier, healthier children, Da Capo Press, Cambridge, MA.

Else, P and Sturrock, G 1998, 'The playground as therapeutic space: playwork as healing', paper presented at Play in a Changing Society: Research, Design, and Application, IPA/USA National Conference, Longmont, CO, 17-21 June.

Federal Trade Commission 2000, Marketing violent entertainment to children: a review of self-regulation and industry practices in the motion picture, music recording, and electronic gaming industries, Federal Trade Commission, Washington, DC.

Fisher, K 2009, 'Playwork in the early years: working in a parallel profession' in Foundations of playwork, ed. F Brown and C Taylor, Open University Press, Maidenhead, pp. 174-178.

Floriani, V and Kennedy, C 2008, 'Promotion of physical activity in children', Current Opinion in Pediatrics, vol. 20, no. 1, pp. 90-95.

Gill, T 2007, No fear: growing up in a risk averse society, Gulbenkian Foundation, London.

Ginsberg, KR 2007, The importance of play in promoting healthy child development and maintaining strong parent-child bonds, American Academy of Pediatrics, IL.

Hofferth, SL 1999, Changes in American children's time, 1981-1997, University of Michigan Press, Ann Arbor, MI.

Hughes, B 1996, Play environments: a question of quality, PLAYLINK, London.

KaBoom 2009, Play matters: a study of best practices to inform local policy and process in support of children's play, KaBoom, Washington, DC. 
Keats, J 1817, Letter to George and Tom, 21 December 1817, http://www.mrbauld.com/negcap.html (accessed 21 November 2005).

Luke, C 1990, Constructing the child viewer: a history of American discourse on television and children, 1950-1980, Praeger, New York, NY.

Mackett, R, Brown, B, Gong, Y, Kitazawa, K and Paskins, J 2009, 'Children's independent movement in the local environment', Built Environment, vol. 33, no. 4, pp. 454-468.

Marano, HE 2008, A nation of wimps: the high cost of invasive parenting, Broadway, New York.

Melville, S 1999, 'Creating spaces for adventure', Built Environment, vol. 25, no. 1, pp. $71-74$

Miller, E. and Almon, J 2009, Crisis in the kindergarten: why children need to play in school, Alliance for Childhood, College Park, MD.

Nicholson, S 1971, 'How not to cheat children: the theory of loose parts', Landscape Architecture Quarterly, vol. 62, no. 1, pp. 30-34.

Parsons, T 1968, Sociological theory and modern society, Free Press, New York.

Patte, MM 2009, 'The state of recess in Pennsylvania elementary schools: a continuing tradition or a distant memory?' in Play and culture studies: transactions at play, vol. 9, ed. C Dell-Clark, University Press of America, Lanham, MD, pp. 147-165.

Pink, DH 2005, A whole new mind: why right-brainers will rule the future, Riverhead Books, New York.

Play Safety Forum 2008, Managing risk in play provision: a position statement, National Children's Bureau, London.

Portchmouth, J 1969, Creative crafts for today, Studio Vista, London.

Rideout, VJ, Vandewater, EA and Wartella, EA 2003, Zero to six: electronic media in the lives of infants, toddlers, and pre-schoolers, Kaiser Family Foundation, Menlo Park, CA.

Robert Wood Johnson Foundation 2009, Active education: physical education, physical activity, and academic performance, Robert Wood Johnson Foundation: San Diego, CA.

Sallis, JF and Glanz, K 2006, 'The role of built environments in physical activity, eating, and obesity in childhood', Future of Children, vol. 16, no. 1, pp. 89108 , 
http://www.futureofchildren.org/futureofchildren/publications/docs/16_01_0 5.pdf (accessed 11 June 2011).

Sanjek, R (ed.) 1990, Fieldnotes; the makings of anthropology, Cornell University Press, Ithaca, NY.

Sigel, IE 1987, 'Does hothousing rob children of their childhood?' Early Childhood Research Quarterly, vol. 2, pp. 211-225.

Smith, A 1976 [1759], The theory of moral sentiments, ed. DD Raphael and AL Macfie, Clarendon Press, Oxford.

Stanford University School of Medicine 2007, Building generation play: addressing the crisis of inactivity among America's children, Stanford University School of Medicine, Palo Alto, CA.

Stern, DN 1985, The interpersonal world of the infant: a view from psychoanalysis and developmental psychology, Basic Books, New York.

Sturrock, G 2007, ‘Towards tenets of playwork practice', iP-DiP, no. 1, pp. i-iv.

Sutton-Smith, B 1997, The ambiguity of play, Harvard University Press, Cambridge, MA.

Sutton-Smith, B 1999, 'Evolving a consilience of play definitions: playfully' in Play and culture studies, vol. 2, ed. S Reifel, University Press of America, Lanham, MD, pp. 239-256.

Trevarthen, C 1996, 'How a young child investigates people and things: why play helps development', keynote speech to TACTYC Conference, London, November.

United Nations International Children's Emergency Fund 1991, United Nations Convention on the Rights of the Child, UNICEF Kommitten, Svenska. 